\title{
Clinical conditions during severe hypoglycemia in patients with diabetes
}

\author{
Tetsuro Tsujimoto $\cdot$ Ritsuko Yamamoto-Honda
}

Received: 28 January 2014/Published online: 15 March 2014

(C) The Japan Diabetes Society 2014

Keywords Severe hypoglycemia $\cdot$ Diabetes $\cdot$ Severe hypertension · Hypokalemia $\cdot$ QT prolongation .

Cardiovascular events

\section{Introduction}

Hypoglycemia has been recognized as a dangerous condition that can lead to convulsions, impaired awareness, and traffic accidents [1]. However, the ACCORD trial [2], in which strict glucose control resulted in increased mortality, triggered further research about the association between hypoglycemia and the risk of death and cardiovascular disease. Thus, many investigations about hypoglycemia have been conducted, and severe hypoglycemia has been recognized as one of the most serious problems in patients with diabetes [3-6]. Severe hypoglycemia is defined as the presence of any hypoglycemic symptoms that cannot be resolved by the patients themselves. Some studies have suggested that diabetes and severe hypoglycemia are associated with increased mortality and cardiovascular disease [3,4]. Although systemic conditions and complications during severe hypoglycemia have remained unclear, recent studies have revealed the clinical presentation during severe hypoglycemia in patients with type 1 and type 2 diabetes [6-10].

T. Tsujimoto $(\bowtie) \cdot R$. Yamamoto-Honda Department of Diabetes, Endocrinology, and Metabolism, National Center for Global Health and Medicine, Tokyo, Japan e-mail: ttsujimoto@hosp.ncgm.go.jp

T. Tsujimoto

Division of General Medicine, Jichi Medical University

Graduate School of Medicine, Tochigi, Japan

\section{Disorders of consciousness and hypothermia}

Hypoglycemia leads to disorders of consciousness, and lower blood glucose levels are associated with lower Glasgow Coma Scale scores [6]. Hypoglycemia cannot only lower the activity in brain cells but also influence the thermoregulatory center in the hypothalamus. A recent study suggested that hypothermia is not uncommon with hypoglycemia [6,11]; about $20 \%$ of patients with type 1 or type 2 diabetes exhibited hypothermia (body temperature $<35{ }^{\circ} \mathrm{C}$ ) during severe hypoglycemia [6].

\section{Severe hypertension}

Hypoglycemia stimulates the sympathetic nervous system and the secretion of counter-regulatory hormones, such as epinephrine and norepinephrine, which can lead to changes in circulatory dynamics. In patients with type 2 diabetes, most of them actually experience blood pressure elevation and severe hypertension during severe hypoglycemia [6]. However, type 1 diabetic patients did not show the same significant elevation in their blood pressure as type 2 diabetic patients did. One of the possible reasons is that patients with type 1 diabetes typically experience hypoglycemia more frequently than those patients with type 2 diabetes, and these repeated hypoglycemic episodes lead to hypoglycemiaassociated autonomic failure, which may blunt the sympathetic system response to hypoglycemia [12].

\section{Hypokalemia}

Patients with type 1 and type 2 diabetes present with hypokalemia during severe hypoglycemia [6]. Because the 
primary causes of severe hypoglycemia in patients with type 1 and type 2 diabetes are antihyperglycemic agents such as insulin and sulfonylureas, the potassium in the extracellular fluid may be transferred to the intracellular fluid by the relative hyperinsulinemia caused by these agents, as well as by the release of catecholamines that can be induced by severe hypoglycemia. Although hypokalemia due to severe hypoglycemia has hardly appeared as a problem, hypokalemia can lead to deadly arrhythmias, and therefore hypokalemia may be another threat during severe hypoglycemia.

\section{Prolonged QT interval}

The association between QT prolongation and hypoglycemia in patients with type 1 diabetes has been previously reported $[8,10,13]$. However, patients with type 2 diabetes may also have QT prolongation during severe hypoglycemia [6]. Although the possible cause for QT prolongation may be hypercatecholaminemia, hypothermia, and hypokalemia due to severe hypoglycemia, further research is required to establish the detailed mechanism of this process. QT prolongation can lead to lethal arrhythmias such as torsade de pointes. In addition, QT prolongation may also be associated with the onset of atrial fibrillation [6, 14].

\section{Cardiovascular events during severe hypoglycemia}

Newly diagnosed cardiovascular events during severe hypoglycemia have been found in a small but significant minority of patients with type 2 diabetes [6]. Although the causal relationship is unknown, severe hypoglycemia may lead to cardiovascular events because of a significant cardiac load and its exacerbation in the atherosclerotic lesion [15], platelet agglutination [16], and vascular endothelial impairment [17]. In contrast, the association between severe hypoglycemia and cardiovascular events in patients with type 1 diabetes has been not found $[6,18]$. The possible reasons for this finding may be the hypoglycemiaassociated autonomic failure and/or the presence of fewer cardiac risk factors in patients with type 1 diabetes.

In summary, type 1 and type 2 diabetic patients with severe hypoglycemia may develop critical conditions such as cardiovascular disease, lethal arrhythmias, and death. More attention is required to study the fact that the complications associated with severe hypoglycemia may develop under conditions of disturbed consciousness.

Conflict of interest The authors have no conflicts of interest to report.

\section{References}

1. Malouf R, Brust JC. Hypoglycemia: causes, neurological manifestations, and outcome. Ann Neurol. 1985;17:421-30.

2. Action to Control Cardiovascular Risk in Diabetes Study Group, Gerstein HC, Miller ME, Byington RP, Goff DC Jr, Bigger JT, Buse JB, Cushman WC, Genuth S, Ismail-Beigi F, Grimm RH Jr, Probstfield JL, Simons-Morton DG, Friedewald WT. Effects of intensive glucose lowering in type 2 diabetes. $\mathrm{N}$ Engl J Med. 2008;358:2545-59.

3. Bonds DE, Miller ME, Bergenstal RM, Buse JB, Byington RP, Cutler JA, Dudl RJ, Ismail-Beigi F, Kimel AR, Hoogwerf B, Horowitz KR, Savage PJ, Seaquist ER, Simmons DL, Sivitz WI, Speril-Hillen JM, Sweeney ME. The association between symptomatic, severe hypoglycaemia and mortality in type 2 diabetes: retrospective epidemiological analysis of the ACCORD study. BMJ. 2010;340:b4909.

4. Zoungas S, Patel A, Chalmers J, de Galan BE, Li Q, Billot L, Woodward M, Ninomiya T, Neal B, MacMahon S, Grobbee DE, Kengne AP, Marre M, Heller S, ADVANCE Collaborative Group. Severe hypoglycemia and risks of vascular events and death. N Engl J Med. 2010;363:1410-8.

5. Hsu PF, Sung SH, Cheng HM, Yeh JS, Liu WL, Chan WL, Chen $\mathrm{CH}$, Chou P, Chuang SY. Association of clinical symptomatic hypoglycemia with cardiovascular events and total mortality in type 2 diabetes: a nationwide population-based study. Diabetes Care. 2013;36:894-900.

6. Tsujimoto T, Yamamoto-Honda R, Kajio H, Kishimoto M, Noto H, Hachiya R, Kimura A, Kakei M, Noda M. Vital signs, QT prolongation, and newly diagnosed cardiovascular disease during severe hypoglycemia in type 1 and type 2 diabetic patients. Diabetes Care. 2014;37:217-25.

7. Feldman-Billard S, Massin P, Meas T, Guillausseau PJ, Heron E. Hypoglycemia-induced blood pressure elevation in patients with diabetes. Arch Intern Med. 2010;170:829-31.

8. Rossing P, Breum L, Major-Pedersen A, Sato A, Winding H, Pietersen A, Kastrup J, Parving HH. Prolonged QTc interval predicts mortality in patients with Type 1 diabetes mellitus. Diabet Med. 2001;18:199-205.

9. Robinson RT, Harris ND, Ireland RH, Lee S, Newman C, Heller SR. Mechanisms of abnormal cardiac repolarization during insulin-induced hypoglycemia. Diabetes. 2003;52:1469-74.

10. Gruden G, Giunti S, Barutta F, Chaturvedi N, Witte DR, Tricarico M, Fuller JH, Cavallo Perin P, Bruno G. QTc interval prolongation is independently associated with severe hypoglycemic attacks in type 1 diabetes from the EURODIAB IDDM complications study. Diabetes Care. 2012;35:125-7.

11. Tran C, Gariani K, Herrmann FR, Juan L, Philippe J, Rutschmann OT, Vischer UM. Hypothermia is a frequent sign of severe hypoglycaemia in patients with diabetes. Diabetes Metab. 2012;38:370-2.

12. Cryer PE. Diverse causes of hypoglycemia-associated autonomic failure in diabetes. N Engl J Med. 2004;350:2272-9.

13. Christensen TF, Tarnow L, Randløv J, Kristensen LE, Struijk JJ, Eldrup E, Hejlesen OK. QT interval prolongation during spontaneous episodes of hypoglycaemia in type 1 diabetes: the impact of heart rate correction. Diabetologia. 2010;53:2036-41.

14. Nielsen JB, Graff C, Pietersen A, Lind B, Struijk JJ, Olesen MS, Hauns $\emptyset$ S, Gerds TA, Svendsen JH, Køber L, Holst AG. J-shaped association between QTc interval duration and the risk of atrial fibrillation: results from the Copenhagen ECG Study. J Am Coll Cardiol. 2013;61:2557-64.

15. Desouza C, Salazar H, Cheong B, Murgo J, Fonseca V. Association of hypoglycemia and cardiac ischemia: a study based on continuous monitoring. Diabetes Care. 2003;26:1485-9. 
16. Collier A, Patrick AW, Hepburn DA, Bell D, Jackson M, Dawes J, Frier BM. Leucocyte mobilization and release of neutrophil elastase following acute insulin-induced hypoglycaemia in normal humans. Diabet Med. 1990;7:506-9.

17. Jin WL, Azuma K, Mita T, Goto H, Kanazawa A, Shimizu T, Ikeda F, Fujitani Y, Hirose T, Kawamori R, Watada H. Repetitive hypoglycaemia increases serum adrenaline and induces monocyte adhesion to the endothelium in rat thoracic aorta. Diabetologia. 2011;54:1921-9.

18. Gruden G, Barutta F, Chaturvedi N, Schalkwijk C, Stehouwer CD, Witte DR, Fuller JH, Perin PC, Bruno G. Severe hypoglycemia and cardiovascular disease incidence in type 1 diabetes: the EURODIAB Prospective Complications Study. Diabetes Care. 2012;35:1598-604. 